\title{
Distribution and abundance of sardine (Sardina pilchardus) eggs in the English Channel from Continuous Plankton Recorder sampling, 1958-1980
}

\author{
S.H. Coombs $*^{\ddagger}$, N.C. Halliday* ${ }^{\dagger}$, A.J. Southward* and S.J. Hawkins* \\ * Marine Biological Association of the United Kingdom, The Laboratory, Citadel Hill, Plymouth, PL1 2PB, UK. \\ ${ }^{\dagger}$ Sir Alister Hardy Foundation for Ocean Science, The Laboratory, Citadel Hill, Plymouth, PL1 2PB, UK. \\ ${ }^{\ddagger}$ Corresponding author, e-mail: shc@mba.ac.uk
}

\begin{abstract}
Continuous Plankton Recorder (CPR) samples from the English Channel and adjacent Celtic shelf, taken over the period 1958-1980, were analysed for sardine (Sardina pilchardus) eggs. Results showed the progression of sardine spawning along the English Channel from west to east from March to August and a return from east to west from September to November. This corresponds with the two seasonal peaks of sardine egg abundance in the western Channel: the main summer peak being in May/June, with a smaller autumn peak in October/November. Long-term changes in sardine egg abundance in CPR samples showed a decline in summer spawning from the late 1960s, but no clear trend in autumn-spawned egg abundance. Similar patterns were observed in the numbers of sardine eggs sampled by conventional plankton net tows at the time-series Station L5 off Plymouth. This supports the use of the longer timeseries of sardine egg data at L5 as being representative of a wider area and emphasizes the importance in continuation of the L5 time-series.
\end{abstract}

\section{INTRODUCTION}

Spawning of sardine (Sardina pilchardus, Walbaum), also commonly known as the pilchard, has been observed regularly throughout the English Channel and adjacent regions. Corbin (1947) showed egg distributions from April to July extending from the western Channel across the Celtic Plateau. Cushing (1957) plotted egg distributions progressing eastwards up the Channel from April to July, with similar findings being described by Haynes \& Nichols (1994). Extensive surveys from May to July by Wallace \& Pleasants (1972) showed the continuity of spawning from the Biscay shelf through the Celtic Plateau and Channel to the southern North Sea.

Long-term annual changes in sardine egg abundance in the English Channel have been described in a series of papers based on sampling at standard stations off Plymouth since the 1920 s. The more recent summaries of these results are in Southward et al. (1988, 1995) and Southward \& Boalch (1988). In these papers, a decline in the generally more abundant summer-spawned eggs (May-July) was shown from around the 1960s and a relative increase in the less abundant autumn spawning (October-November). Various hydro-climatic and biological indices have been related to these fluctuations which form part of a coherent response of the English Channel ecosystem to climatic change (Southward, 1963, 1980; Russell et al., 1971; Hawkins et al., 2003; Southward et al., 2004).

Continuous Plankton Recorder (CPR) sampling (Reid et al., 2003) has been carried out in the English Channel since the late $1950 \mathrm{~s}$. Routine CPR analysis does not identify fish eggs to species, although sardine eggs are readily distinguishable. The aim of the present work was, therefore, to analyse CPR samples taken in the English Channel and adjacent Celtic Plateau for sardine eggs. These results were then used to describe the egg distributions through the year and to examine whether similar inter-annual trends in sardine spawning, as seen in the Plymouth time-series station results, are observed over a wider sampling area.

\section{MATERIALS AND METHODS}

Continuous Plankton Recorders are towed at approximately monthly intervals by merchant ships along standard routes, with coverage varying from month to month and year to year, depending on ship availability. Sampling is at approximately $7 \mathrm{~m}$ depth, with the plankton being filtered at around $3 \mathrm{~m}^{3}$ per 10 nautical miles of tow (the standard sample size) on a continuously moving band of filtering gauze (nominal $280 \mu \mathrm{m}$ mesh aperture) inside the CPR. The samples are analysed routinely for their plankton content and, as a special exercise for this study, for sardine eggs on samples taken in the English Channel and adjacent areas over the period 1958-1980 (Figure 1A). A full description of the CPR Survey is given in Reid et al. (2003).

Each CPR sample is allocated to a $1^{\circ} \times 2^{\circ}$ rectangle of latitude and longitude (Figure 1A), based on the mid-point of sampling, enabling rectangle monthly means of sardine egg abundance to be calculated for each month; this being the number of eggs divided by the number of samples in each rectangle. For each month, these rectangle monthly means were summed for all rectangles in the study area (Figure 1A) and divided by the number of sampled rectangles for that month, to give standard area monthly means. For plots of 


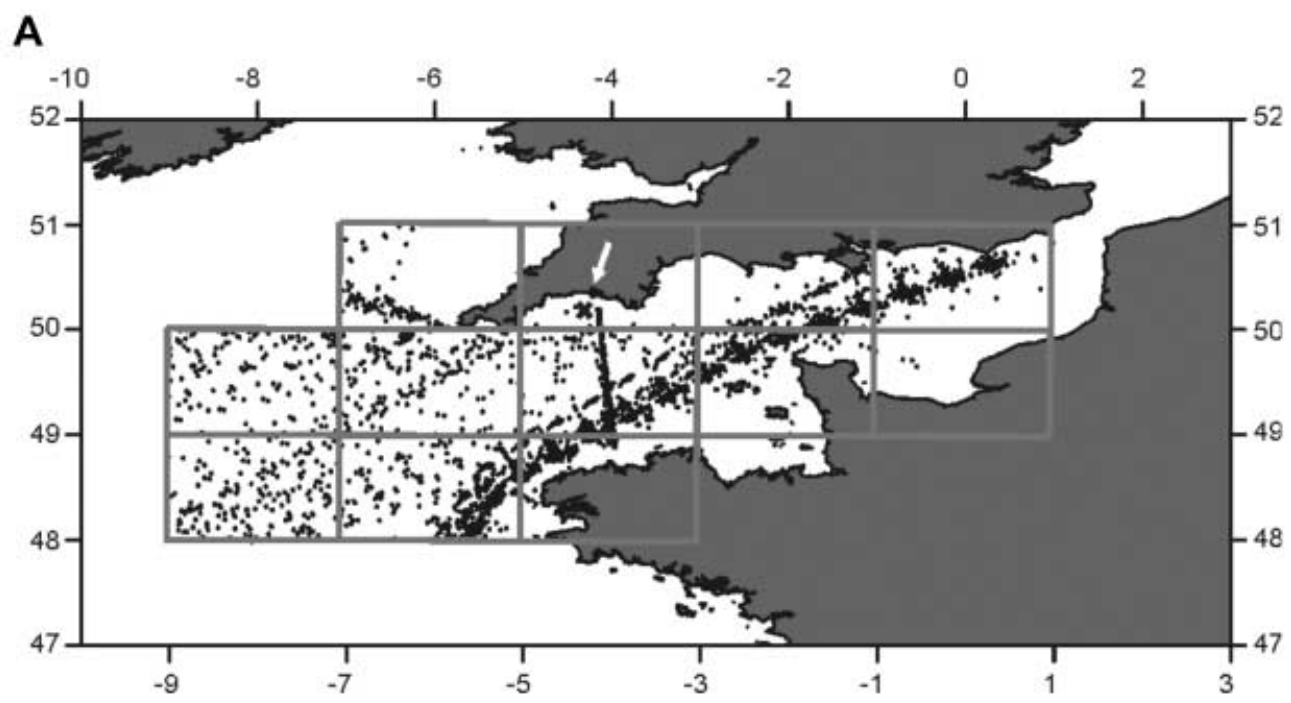

B

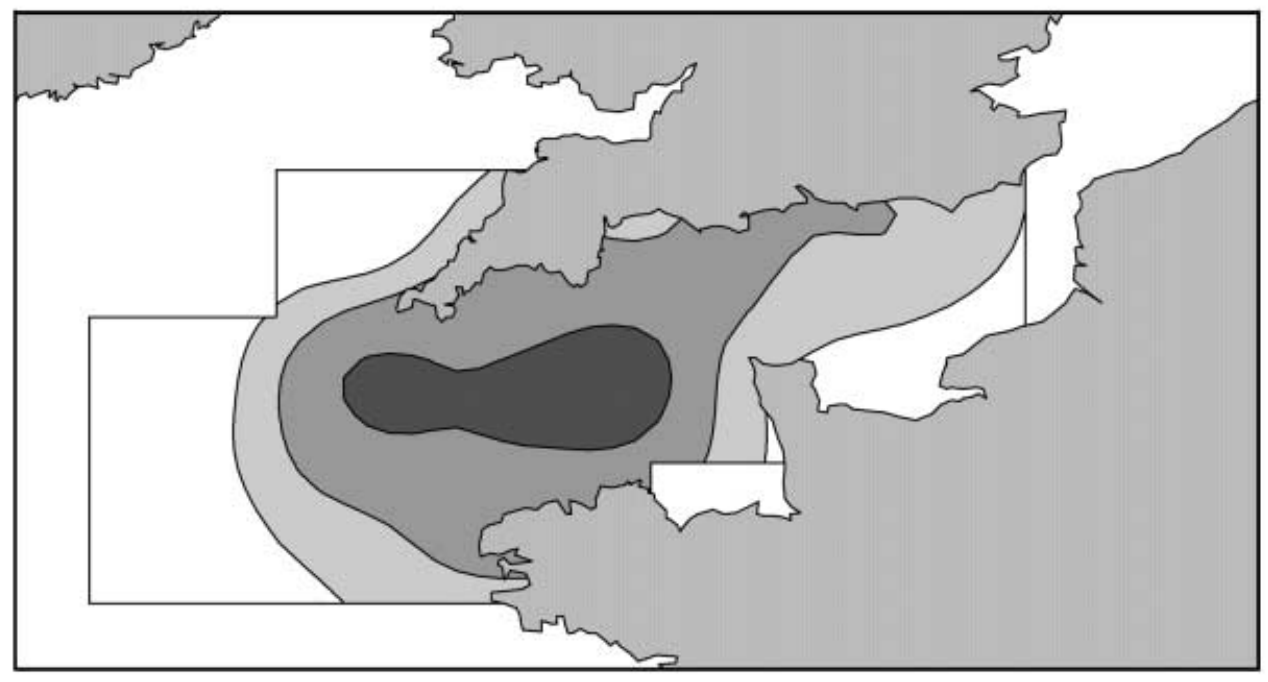

Figure 1. (A) Continuous Plankton Recorder samples (dots) taken over the period 1958-1980 and the standard rectangles used for data processing; the position of the Plymouth L5 time-series station (cross) is indicated by the arrow; (B) overall distribution of sardine eggs in Continuous Plankton Recorder sampling for all months over the period 1958-1980 based on long-term rectangle annual means (contour levels of 1.25, 2.5 and 5.0 eggs per CPR sample).

monthly distribution averaged over the entire sampling period, for each rectangle the rectangle monthly means were summed by month for all years and divided by the number of months the rectangle was sampled, to give a long-term rectangle monthly mean. Finally, to give an overall distribution chart, for each rectangle, the rectangle monthly means were summed for all months and divided by the number of months each rectangle was sampled (long-term rectangle annual mean).

Missing (i.e. when sampling was inadequate or there was none) GPR standard area monthly mean data in the contoured month/year diagram, were interpolated for each month based on the mean of the ten values in the same month for the nearest adjacent sampled years; this value was raised or lowered according to the ratio of the sum of the monthly means for the sampled months in the target year to the sum of the monthly means for the same months for the nearest adjacent ten years which had sampling in each of these months. For 1962 and 1970, unadjusted ten year monthly mean values were used for interpolation because there was insufficient sampling in both these years to provide a correction factor.

The basic data for sardine egg abundance at time-series Station L5, approximately 10 nautical miles offshore from Plymouth (Figure 1A) are presented as monthly means in Southward et al. (1988, 1989). Plankton samples were taken on oblique hauls in the top $50 \mathrm{~m}$ of the water column at approximately weekly intervals using variants of $1 \mathrm{~m}$ or $2 \mathrm{~m}$ circular or square framed nets with a mesh size of around $700 \mu \mathrm{m}$. Results have been standardized to $4000 \mathrm{~m}^{3}$ of water filtered and averaged to give monthly means. A similar interpolation procedure for the L5 


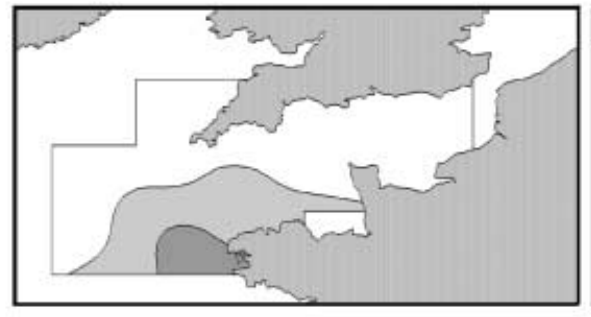

March

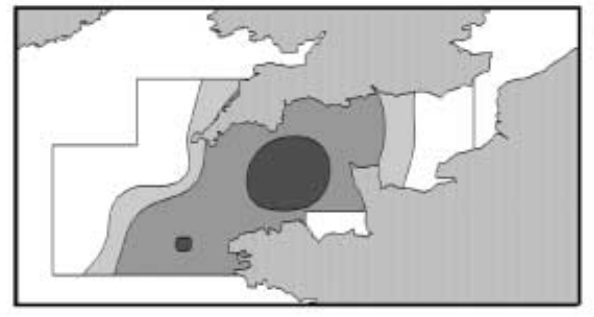

June

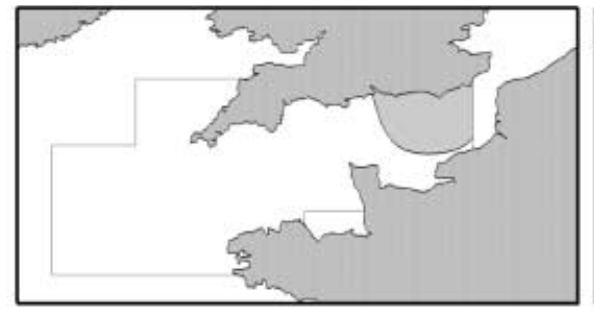

September

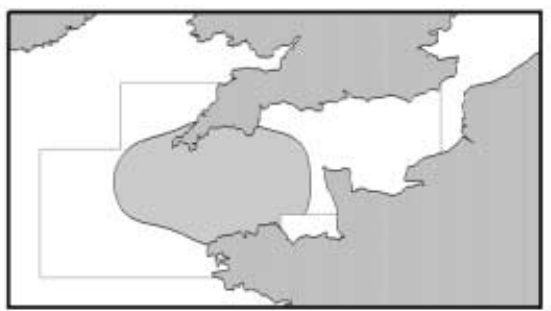

April

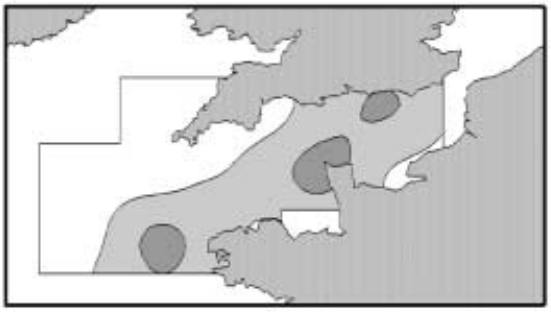

July

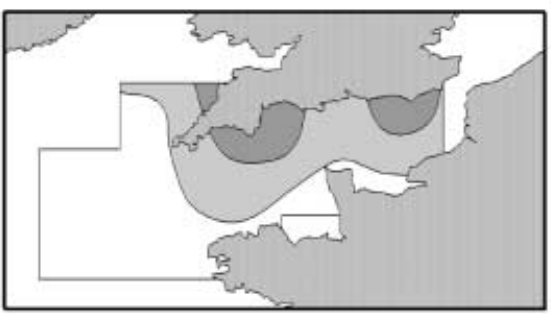

October

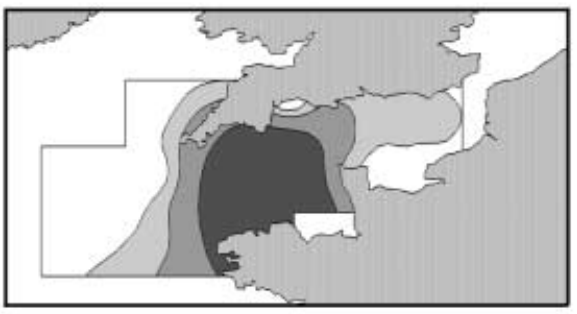

May

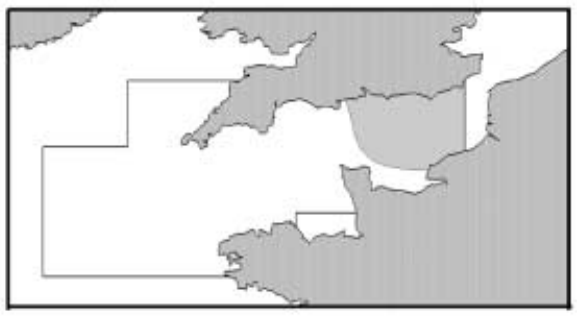

August

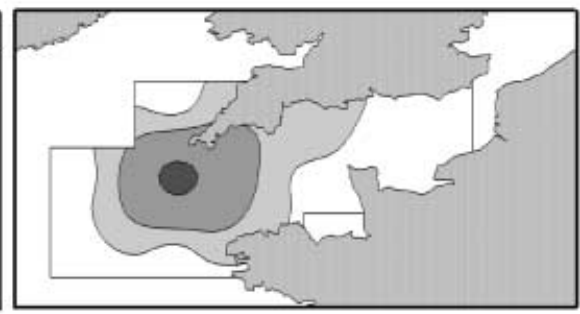

November

Figure 2. Monthly distributions of sardine eggs in Continuous Plankton Recorder sampling over the period $1958-1980$ based on long-term rectangle monthly means (contour levels of 0.1, 0.6 and 2.0 eggs per CPR sample).

CPR

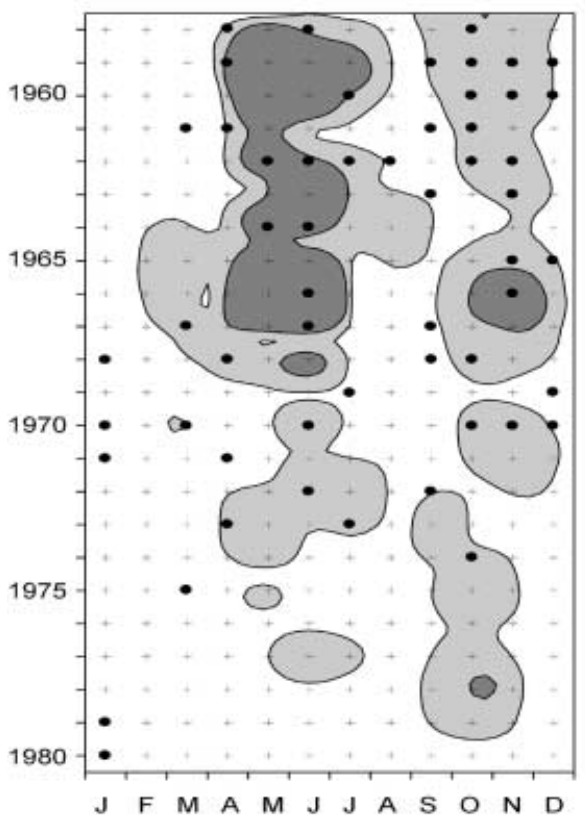

L5

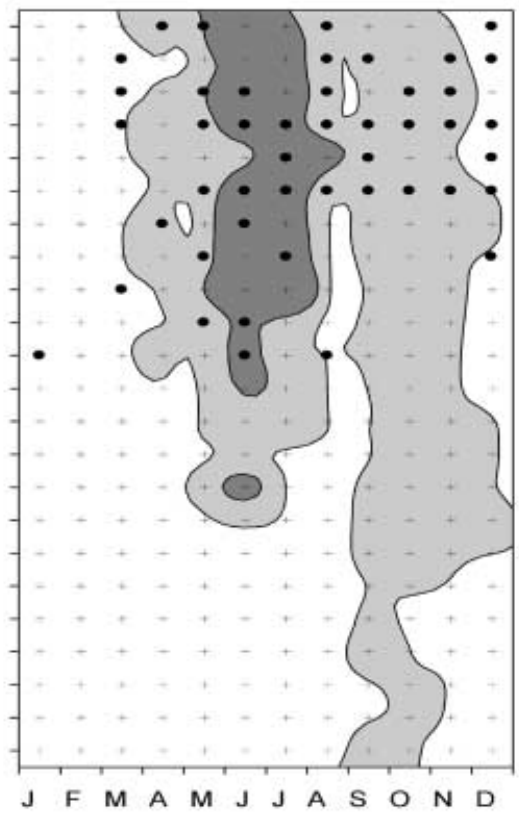

Figure 3. Contoured $\left(\right.$ Surfer $\left.^{\circledR}\right)$ monthly abundance of sardine eggs from CPR sampling (based on standard area monthly means with contour intervals of 1 and 10 eggs per CPR sample) and from net sampling at the Plymouth time-series Station L5 (see FigurelA, contour intervals of 500 and 5000 eggs per standard net tow). The black dots indicate months for which interpolated values were used. 


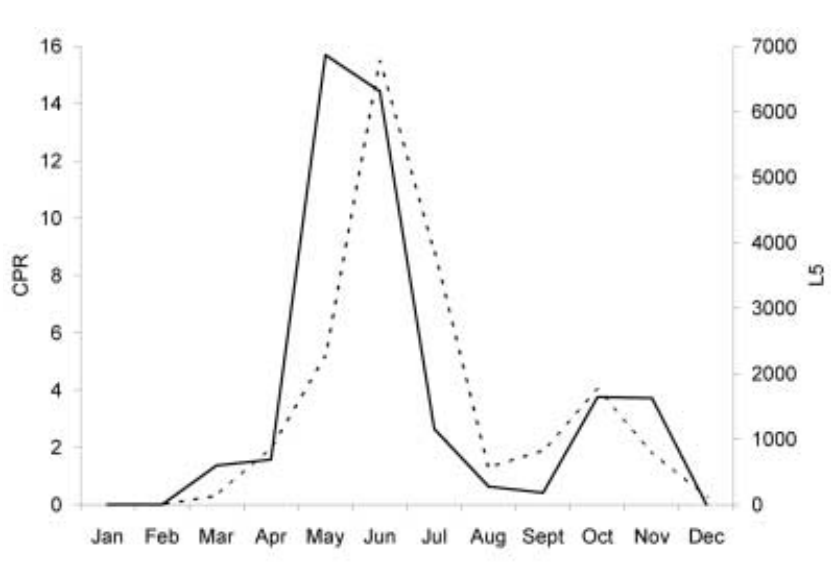

Figure 4. Mean monthly abundance over the period 19581980 of sardine eggs in Continuous Plankton Recorder sampling based on standard area monthly means (continuous line) and at the Plymouth time-series Station L5 based on monthly mean egg numbers per standard tow (dashed line).

contoured month/year diagram was used as for the CPR data. For 1961 and 1963, un-adjusted ten year monthly mean values were used for interpolation because there was insufficient sampling in both these years to give a correction factor.

\section{RESULTS}

\section{Distribution, seasonal occurrence and long-term trends}

The overall distribution of sardine eggs for all months combined, showed the main concentration centred in the western English Channel (Figure 1B). On a monthly basis, eggs first appeared in the south-west of the sampled area in March/April, then extended eastwards up the Channel in greater abundance in May, June and July, before declining to relatively low concentrations in the eastern Channel in August and September (Figure 2). In October, higher egg numbers returned throughout much of the Channel, followed in November by a shift in the main concentration to the western Channel.

The contoured monthly CPR egg abundance by years (Figure 3) shows a decline in summer spawning from the late 1960s, but without any clear trend in autumnspawned egg abundance. Similar patterns were observed in the L5 time-series station data (Figure 3; $\mathrm{R}=0.59$, $P<0.01$ for correlation between CPR and L5 annual abundance, excluding data for 1961, 1962, 1963 and 1970).

Averaged over all years (1958-1980), the main spawning season is seen as the summer peak of egg abundance, which occurs in May/June/July in the L5 station data and slightly earlier, in May/June in the wider coverage of the CPR data (Figure 4). The autumn spawning is in September/October/November in the L5 data and in October/November in the CPR data.

\section{DISCUSSION}

The extensive coverage of CPR sampling provides a broad-scale summary of sardine spawning in the English Channel and consolidates previous findings on distribution and seasonal occurrence derived from more local or individual surveys (e.g. Wallace \& Pleasants, 1972).
The seasonal pattern of egg distribution indicates a wave of spawning progressing eastwards up the Channel in the summer and retreating back to the west in the autumn, hence the two spawning peaks at Plymouth. Although this is consistent with migration of a single population, this view being favoured by Cushing (1957) and Furnestin (1944), it does not discount the possibility of distinct summer and autumn races (Demir \& Southward, 1974). Both Cushing (1957) and Haynes \& Nichols (1994) suggested the progression of spawning was related to seasonal warming. This is true also, in general terms, for the CPR results, but without any striking correspondence with any particular isotherm (Dietrich, 1962).

Similar patterns of seasonal and long-term changes in abundance of sardine eggs were observed between the CPR results from sampling throughout the English Channel and adjacent areas and results from time-series Station L5 off Plymouth. Demir \& Southward (1974) had earlier shown a reasonable agreement between estimates of seasonal duration and intensity of sardine spawning at Station L5 and sampling at an intermediate scale on a surrounding $20 \times 40$ nautical mile grid. The validation of the L5 sardine egg data over a wider area endorses their use for interpretation of environmental change at a regional scale and highlights the importance in continuation of the sampling series.

The agreement between the CPR and L5 datasets is found despite the different sampling methods; the CPR samples only the upper 5-10 m of the water column, which is above the summer thermocline, whereas the L5 sampling includes most of the water column. The agreement between the two datasets is probably due, in part, to the positive buoyancy of sardine eggs (Coombs et al., 2004), which tend to concentrate in the upper water column and are sampled effectively by the shallow CPR tows.

Taking account of the full time-series of sardine egg data available from Station L5 (1930s-present), the changes evident in the CPR results can be seen as part of longer-term cycles of variations in relative numbers of summer and autumn sardine eggs, which were both at a notable low phase of abundance in the late 1970s and early 1980s (Southward \& Boalch, 1988). The declining phase of egg abundance from the late 1960s until the early 1980s parallels a trend of cooling seawater temperatures in the English Channel (Southward \& Boalch, 1988; Hawkins et al., 2003), which is consistent with the decline in spawning of sardine towards the northern limit of its distribution.

The assistance of all personnel involved in the towing of Continuous Plankton Recorders, plankton analysis and data preparation is gratefully acknowledged. Martin Keen is thanked for his help with the CPR analysis. Support for this work has been provided by the EU SARDYN project (S.H.C. and N.C.H.), by Defra and other consortia members via the MECN and MARCLIM programmes (A.J.S. and S.J.H.) and by a NERC funded MBA fellowship (S.J.H.).

\section{REFERENCES}

Coombs, S.H., Boyra, G., Rueda, L.D., Uriarte, A., Santos, M., Conway, D.V.P. \& Halliday, N.C., 2004. Buoyancy measurements and vertical distribution of eggs of sardine (Sardina pilchardus) and anchovy (Engraulis encrasicolus). Marine Biology, 145, 959-970. 
Corbin, P.G., 1947. The spawning of mackerel, Scomber scombrus L., and pilchard, Clupea pilchardus Walbaum, in the Celtic Sea in 1937-39. Journal of the Marine Biological Association of the United Kingdom, 28, 65-132.

Cushing, D.H., 1957. The number of pilchards in the Channel. Fishery Investigations, Ministry of Agriculture Fisheries and Food, Series 2, 21, 1-27.

Demir, N. \& Southward, A.J., 1974. The abundance and distribution of eggs and larvae of Teleostean fishes off Plymouth in 1969 and 1970. Part 3. Eggs of pilchard (Sardina pilchardus Walbaum) and sprat (Sprattus sprattus (L.)). Fournal of the Marine Biological Association of the United Kingdom, 54, 333-353.

Dietrich, G., 1962. Mean monthly temperature and salinity of the surface layer of the North Sea and adjacent waters from 1905 to 1955. International Council for the Exploration of the Seas, Hydrographic Service, Copenhagen, 320 pp.

Furnestin, J., 1944. Contribution à l'etude biologique de la Sardine Atlantique (Sardina pilchardus Walbaum). Revue des Travaux d'Office Scientifique et Technique des Pêches Maritimes, 13, 221-386.

Hawkins, S.J., Southward, A.J. \& Genner, M.J., 2003. Detection of environmental change in a marine ecosystem-evidence from the western English Channel. Science of the Total Environment, 310, 245-256.

Haynes, G.M. \& Nichols, J.H., 1994. Pilchard (Sardina pilchardus, Walbaum) egg distribution in the English Channel from plankton surveys in 1978, 1981, 1988 and 1991. Fournal of Plankton Research, 16, 771-782.

Reid, P.C., Matthews, J.B.L. \& Smith, M.A., 2003. Achievements of the Continuous Plankton Recorder Survey and a vision for its future. Progress in Oceanography, 58, 115-358.

Russell, F.S., Southward, A.J., Boalch, G.T. \& Butler, E.I., 1971. Changes in biological conditions in the English Channel off Plymouth during the last half-century. Nature, London, 234, 468-470.
Southward, A.J., 1963. The distribution of some plankton animals in the English Channel. Fournal of the Marine Biological Association of the United Kingdom, 43, 1-29.

Southward, A.J., 1980. The western English Channel-an inconstant ecosystem? Nature, London, 285, 361-366.

Southward, A.J. \& Boalch, G.T., 1988. Aspects of long term changes in the ecosystem of the western English Channel in relation to fish populations. In Proceedings of the International Symposium on Long Term Changes in Marine Fish Populations, Vigo, Spain, November 1986 (ed. T. Wyatt and M.G. Larraneta), pp. 415-447. Vigo: Instituto Investigaciones Marinas.

Southward, A.J., Boalch, G.T. \& Maddock, L., 1988. Fluctuations in the herring and pilchard fisheries of Devon and Cornwall linked to change in climate since the 16th century. Fournal of the Marine Biological Association of the United Kingdom, 68, 423-445.

Southward, A.J., Hawkins, S.J. \& Burrows, M.T., 1995. Seventy years' observations of changes in distribution and abundance of zooplankton and intertidal organisms in the western English Channel in relation to rising sea temperature. Fournal of Thermal Biology, 20, 127-155.

Southward, A.J. et al., 2004. Long-term oceanographic and ecological research in the western English Channel. Advances in Marine Biology, 47, 1-105.

Wallace, P.D. \& Pleasants, C.A., 1972. The distribution of eggs and larvae of some pelagic fish species in the English Channel and adjacent waters in 1967 and 1968. International Council for the Exploration of the Sea (CM Papers and Reports), GM 1972/J: 8, 4 pp. 